ORIGINAL ARTICLE

\title{
Effectiveness of a supervised physical activity programme on physical activity adherence in patients with cardiovascular risk factors ${ }^{\text {is }}$
}

\author{
Alba Pardo ${ }^{\mathrm{a}, \mathrm{b}, *}$, Mariona Violán ${ }^{\mathrm{a}}$, Carmen Cabezas ${ }^{\mathrm{c}}$, Juanjo García ${ }^{\mathrm{d}}$, Carles Miñarro ${ }^{\mathrm{a}, \mathrm{e}}$, \\ Maica Rubinat ${ }^{\mathrm{a}}$, Angelina González ${ }^{\mathrm{c}}$, Blanca Romàn-Viñas ${ }^{\mathrm{a}, \mathrm{f}, \mathrm{g}}$
}

a Consell Català de l'Esport, Grup PAFES (Pla d'Activitat Física, Esport i Salut), Esplugues de Llobregat, Barcelona, Spain

b Institut Nacional d'Educació Física de Catalunya (INEFC-Barcelona), Universitat de Barcelona, Barcelona, Spain

c Generalitat de Catalunya, Agència de Salut Pública de Catalunya, Barcelona, Spain

d Universitat Pompeu Fabra, Scientific Communication Research Group, Barcelona, Spain

e Centre d'Alt Rendiment (CAR), Unitat Assistencial i Preventiva de l'Esport, Sant Cugat, Barcelona, Spain

${ }^{f}$ Escola Universitària de Salut i Esport (EUSES), Girona, Spain

g Universitat Ramon Llull, Departament de Ciències de l'Activitat Física i l'Esport, Barcelona, Spain

Received 11 October 2013; accepted 3 February 2014

Available online 14 April 2014

\section{KEYWORDS}

Physical activity;

Physical activity

referral scheme;

Prescription;

Adherence;

Primary care;

Quality of life

\begin{abstract}
Introduction: Physical activity referral schemes (PARS) in primary care centres increase the level of physical activity (PA) in the general population. However, few studies assess PA adherence after interventions. This study aimed at: (i) to assess PA adherence after a six-month PARS, and at 12-months (after six months of a follow-up period without intervention), (ii) and to assess the impact of PARS on health-related quality of life (HRQL) in patients with cardiovascular risk factors (CVRF).

Materials and methods: Longitudinal design. A total of 323 patients with $\geq 2$ CVRF, in contemplative stage of change, from 27 primary care centres in Catalonia, were referred during 2010-2011 to a six-month PARS (three sessions/week of 60 min of moderate-intensity PA (MPA)). PA level and HRQL were analysed at baseline, at six-months, and at 12-months follow-up measurement, with the International Physical Activity Questionnaire (short version), and the SF-12, respectively.
\end{abstract}

\footnotetext{
is Article presented at medical conferences: Title: Physical activity referral: Impact on physical activity adherence and health-related quality of life. Presentation format: Mini-Oral. 18th Annual Congress of the European College of Sport Science (ECSS) between 26-29 June 2013 in Barcelona, Spain (Abstr.-ID: 1397).

* Corresponding author.

E-mail address: albapf9@hotmail.com (A. Pardo).
} 
Results: Out of the total number of patients (323), 75\% ( $n=242 ; 62.6 \pm 8.5$ years; $75 \%$ women) completed the PARS, with a mean attendance of $84.1 \%$. A six-month PARS increased PA level, especially MPA and improved HRQL $(p<0.01)$. At 12 -months, the number of physically inactive patients remained lower than baseline; MPA level decreased, and the positive effects on HRQL were retained, especially in social functioning (26.4), physical functioning (18.2), and emotional component (18.3) $(p<0.01)$.

Conclusions: A six-month PARS decrease the number of inactive patients and improves PA level and HRQL. Improvements in physical functioning, social functioning, and emotional component were retained up to one year. PARS appear to be an adequate treatment to improve the health of patients with CVRF.

(C) 2013 Consell Català de l'Esport. Generalitat de Catalunya. Published by Elsevier España, S.L. All rights reserved.

\section{PALABRAS CLAVE}

Actividad física;

Programa de prescripción de actividad física supervisada; Prescripción; Adherencia; Atención primaria; Calidad de vida

\section{Introduction}

Physical activity (PA) is a therapeutic and preventive tool for numerous chronic diseases. Globally, physical inactivity causes $6 \%$ of cardiovascular disease, $7 \%$ of type II diabetes, $10 \%$ of breast cancer, $10 \%$ of colon cancer and $9 \%$ of premature mortality. ${ }^{1}$ The burden of chronic diseases and its resultant cost could be mitigated through a lifestyle medicine, based on including lifestyle behaviour changes.

PA prescription and physical activity referral schemes (PARS) in primary care have been shown to be effective in increasing PA level among general population. ${ }^{2,3}$ In Catalonia a pilot study showed that a three-month PARS based on primary care was sufficient to cause changes in lifestyle from an increased level of PA. ${ }^{4}$ Moreover, Garcia et al. have shown that PA prescription was effective in improving control of risk factors and decreasing cardiovascular risk. ${ }^{5}$

Furthermore, health care providers are in a good position to promote an increase in PA among general population. First because many individuals do contact their physicians each year, in Catalonia, $92.7 \%$ of the population visit a health professional once a year ${ }^{6}$; and second, because health care providers are the preferred source of health information among the general population ${ }^{7}$ and patients trust them.

The Department of Sports and the Department of Health of the Government of Catalonia established in 2007 the Plan of Physical Activity, Sport and Health (PAFES). ${ }^{8}$ The PAFES is a strategy created by the Catalan Government, with the objective to reduce high levels of sedentary behaviours among adult population through the promotion of an active and healthy lifestyle. PAFES is based on the prescription of PA from primary care professionals with the involvement of municipality to increase PA that is offered locally.

The PAFES developed three levels of counselling: (a) PA's brief advice, (b) PA assessment and prescription (through healthy walking routes) and (c) PARS (six-month of an exercise programme, lead and supervised by a PA professional in a sport facility). 
PARS were designed especially for inactive patients presenting cardiovascular risk factors (CVRF). The main objective of PARS was to get the most inactive patients to adhere to the current PA recommendations, i.e. accumulate a minimum of $150 \mathrm{~min} /$ week of moderate-intensity PA (MPA). ${ }^{9}$

Although several studies has shown the effectiveness of a PA intervention based on primary care, there is a lack of evidence regarding their long-term effectiveness in maintaining PA adherence after the finalization of the intervention. ${ }^{3,10,11}$

This study has two aims: (i) to assess PA adherence at 6month of PARS and at 12-month follow-up (six-months after the PARS) and (ii) to assess the impact of PARS on healthrelated quality of life (HRQL) in patients with CVRF.

\section{Materials and methods}

Longitudinal descriptive study based on a sample of patients from 27 primary care centres of Catalonia, which have been referred by their health professional (primary care physician or nurse) to a PARS during 2010-2011.

\section{Participants}

The inclusion criteria for PARS were inactive adults $\geq 45$ years old in the contemplative stage of change (intention to start being physically active in the next 6 months $)^{12}$ and with two or more CVRF as follows: diagnosed with hypertension $(140 / 90$ blood pressure $\mathrm{mmHg}$ or treatment with antihypertensive drugs), diagnosed with type II diabetes, a body mass index $(\mathrm{BMI}) \geq 25 \mathrm{~kg} / \mathrm{m}^{2}$ and/or diagnosed with dyslipidemia. The health professionals excluded anyone with a medical condition that contraindicates exercise according to the PEFS Guide. ${ }^{13}$ The health professionals recruited patients who met any of these criteria during their routine visits and consultation and sports medicine doctors assessed the referred patients to exclude those who presented any contraindication to initiate the exercise programme.

A total of 32 groups of maximum 15 participants $(N=323)$ of 45-80 years were referred by the health professional to PARS. Participants gave informed consent to participate in the study. This study was approved by the Clinical Research Ethics Committee of Sports Administration of the Catalan Government.

\section{Intervention}

PARS consisted in a supervised exercise programme of three sessions of 60 min weekly, combining moderate intensity aerobic activity (MPA), muscular endurance of the major muscle groups with use of equipment (dumbbells and elastic bands) and flexibility. The exercise programme was lead and supervised by a PA professional previously trained. Patients must pay a little fee to participate in the programme.

\section{Measurements and follow-up}

Participants were assessed at baseline, at six-months after PARS and at 12-months follow-up assessment. At baseline and at six-month of PARS, the questionnaires were selfadministered and at 12-month of follow-up patients were interviewed by telephone.

The first outcome measure was the change in selfreported PA level using the shorter version of the International Physical Activity Questionnaire (IPAQ) and validated in the Catalan language. ${ }^{14,15}$ The questionnaire consists of five questions on the frequency and duration of vigorous-intensity PA (one that requires hard physical effort and makes you breathe much harder than normal), moderate-intensity PA (one that requires moderate physical effort and breathe a little stronger than normal), and walking time. It allows to classify individuals according to their level of adherence to current PA recommendations: (1) do not engage in MPA, (2) $<150 \mathrm{~min} /$ week of MPA or (3) $\geq 150 \mathrm{~min} /$ week of MPA.

Two variables were created for PA level. The first, classified subjects according to the minutes that they engage in MPA: (1) do not engage in MPA, (2) <150 min/week of MPA or (3) $\geq 150 \mathrm{~min} /$ week of MPA. A second variable was created by counting the MPA time plus the time spent walking: (1) do not engage in MPA or walking (2) performed <150 min/week of MPA or walking, or (3) $\geq 150 \mathrm{~min} /$ week of MPA or walking.

The second outcome measure was the assessment of the self-perceived HRQL by the SF-12. ${ }^{16}$ It includes 12 questions and generates a health profile of the eight dimensions: physical functioning, physical role limitation, body pain, general health, vitality, social function, emotional role limitation and mental health. It can be summarized into two summary components, physical and mental. The number of response options ranges from three to six and each question is given a value which is then transformed onto a scale from 0 (worst score) to 100 (best). Scores have a mean of 50 with a standard deviation of 10 , so values above or below 50 indicates a better or worse health, respectively, than the general population.

Adherence to PARS was assessed using an attendance list at the exercise sessions and was translated into average percentage of attendance in the programme.

\section{Data analysis}

A descriptive analysis of the baseline characteristics of PA level and HRQL was run. The mean and the standard deviation were calculated in quantitative variables and percentages for qualitative variables. The normal distribution of numerical variables was analyzed using the Kolmogorov-Smirnov test. The Student's $t$-test was used for paired data in order to assess the evolution of intra-group dependent variables before and after the programme; when the distribution of the variables was not normal Wilcoxon test was used. Changes in the different variables, between pre-, post- and at 12 months follow-up assessment, was analysed with the Friedman test.

Statistical significance was set at $p<0.05$. Statistical analysis was performed using SPSS version 18.0 (SPSS Inc., Released 2009. PASW Statistics for Windows Version 18.0, Chicago: SPSS Inc.). 


\section{Results}

\section{Baseline data}

The level of uptake to the intervention was of $75 \%$. Of the 323 participants, 242 completed the PARS. The mean age of the sample was $62.6 \pm 8.5$ years (from 45 to 80 years) and females were more prevalent among the sample (74\%).

Baseline data showed that some participants already reported some type of PA: $41.6 \%$ of the sample engaged in walking activity for $\geq 150$ min weekly and $30.6 \%$ accumulated $\geq 150 \mathrm{~min} /$ week of MPA. Significant differences were found at baseline in gender and age variables. Males engaged in more MPA than females $(p=0.039)$ and adults $(45-64$ years) were more likely to engage in MPA than older adults (65-80 years) $(p=0.038)$.

\section{Post-intervention data}

Mean attendance to PARS sessions was of $84.1 \%$. Table 1 shows pre- and post-intervention values of the variables related to PA level and HRQL. PARS increased by $39.6 \%$ the proportion of patients who engaged in $\geq 150 \mathrm{~min} /$ week $(p<0.001)$, mainly due to an increase of MPA, since no significant differences were found in walking or vigorous-intensity PA time. At the end of the programme, males were more active at MPA (86\% versus $65 \%)$ than females $(p=.005)$. No significant differences were found between PA levels with gender, age or attendance to PARS.

HRQL increased in all dimensions, both physical and emotional summary components $(p<0.01)$, especially in social functioning (5.9), physical functioning (6.7) and in the emotional component (8.9) $(p<0.01)$ (Table 1).

Regarding the dropouts, $16.5 \%$ of drop out during PARS and $7.9 \%$ were missed due to changes in contact address or non-responders. The main reasons for dropout were the worsening of a disease and the perception of more pain. Droppers were predominantly female, slightly younger than the average $(58.9 \pm 1.3$ years versus $62.6 \pm 8.5$ years), more likely to perceive poor health $(72.7 \%$ versus $60.0 \%)$ and were slightly more active than the rest of the sample (average total PA $\mathrm{min}$ /week: $576.8 \pm 612.1$ versus $473 \pm 493.6$ ).

\section{Follow-up data}

PA adherence at 12-months was assessed in a sub-study of 101 patients. After six months of follow-up without intervention, MPA decreased and no changes were observed in walking time. The number of physically inactive patients remains lower than the baseline (34.3\% versus $50 \%)$, showing a decrease of $15.7 \%$ (Table 2 ).

The positive effects on HRQL were retained up to six months after the finalization of the intervention, especially in social functioning (26.4), emotional component (18.3) and physical functioning (18.2) $(p<0.01)$ (Table 2).

The main reason for not following with the exercise prescription after the 6 months-PARS was the lack of continuity in the same exercise groups.

\section{Discussion}

The present study shows the first set of results of one of the PA prescription programme of PAFES. This study extends the knowledge on PA adherence at long-term (six months after the completion of the intervention) and the impact of a PARS on quality of life in patients with CVRF. It is important to assess PA programmes based on health promotion to understand its success or failure and justify its implementation.

The three major findings of this study were that (i) a sixmonth PARS significantly increases PA level in patients with CVRF, (ii) adherence to PA decreases at 12-month assessment and (iii) a six-month PARS improves HRQL up to one year, especially on emotional component, social and physical functioning.

Most of the participants of the present study were females and adults $>60$ years old. Those who dropped out during the intervention were predominantly females. This is in line with a systematic review showing that being female and increasing age were found to be consistent predictors of higher levels of uptake of PARS ${ }^{17}$ and being male and increasing age were found to be consistent predictors of higher levels of adherence to PARS. ${ }^{17,18}$

The presence of barriers to PA practice could explain some of the reason of dropouts. ${ }^{19,20}$ Studies showed that for the older adults and patients with chronic disease, the onset or worsening of a disease is a major reason for leaving and not continuing with a PA intervention ${ }^{18,21}$ together with the feeling of not being identified with the group, and feeling of being intimidated or isolated. ${ }^{20}$ The present sample may have fewer long-term adherences to PA due to their condition as patients with CVRF and their older age. Moreover, females' reasons of non-adherence were predominantly family responsibilities and lack of spousal support. It is then necessary to address barriers such as pain or the lack of motivation or social support.

The adherence to PARS (mean attendance: $84.1 \%$ ) was higher than the results of a systematic review which shows that $45 \%$ of the participants attended at least $75 \%$ of the programme sessions. ${ }^{17}$ The six-month PARS increased up to $40 \%$ the proportion of patients who accumulated $150 \mathrm{~min} /$ week of MPA. A total of $70.2 \%$ achieved the active level ( $\geq 150 \mathrm{~min} /$ week of MPA) after the completion of the intervention. No changes were found in walking time or VPA variables. These results may be explained by the high prevalence of walking habit already at the baseline assessment and the lack of including VPA in PARS' sessions because it was addressed to patients with CVRF.

Results of PA adherence at 12-month were consistent with previous random control trials and systematic reviews $3,10,22,23$ in showing a decrease of changes attained during the intervention. Grandes et al. also showed that physicians were effective in increasing PA level among inactive patients during the initial six-months of an intervention but its effect decline at 12 and 24 months $^{11}$ if the prescription was not repeated over time.

Although PA level decreased at 12-month follow-up assessment, the percentage of inactive patients was lower than baseline (Table 2). The decrease of PA adherence at long-term may be explained by the lack of an ongoing 
Table 1 Changes in physical activity (PA) level and Health-related quality of life, pre- and post-intervention ( $n=242)$.

\begin{tabular}{|c|c|c|c|c|}
\hline Variables $^{a}$ & Pre & Post & $\begin{array}{l}\text { Differences } \\
\text { Wilcoxon test }\end{array}$ & $p^{\mathrm{b}}$ \\
\hline \multicolumn{5}{|l|}{ Physical activity (min/week) } \\
\hline Total PA & $496.5 \pm 491.8$ & $519.6 \pm 412.9$ & 2.2 & 0.027 \\
\hline Vigorous PA & $41.2 \pm 159.6$ & $28.2 \pm 131.4$ & ns & ns \\
\hline Moderate PA (MPA) & $154.7 \pm 277.9$ & $229.9 \pm 202.5$ & 5.8 & $<0.001$ \\
\hline Walking & $299.9 \pm 324.5$ & $261.4 \pm 253.9$ & ns & ns \\
\hline \multicolumn{5}{|l|}{ Physical activity (days/week) } \\
\hline MPA & $1.6 \pm 2.2$ & $3.0 \pm 1.8$ & 7.7 & $<0.001$ \\
\hline Walking & $4.1 \pm 2.7$ & $4.3 \pm 2.5$ & ns & ns \\
\hline MPA and walking $(n(\%))$ & & & 5.5 & $<0.001$ \\
\hline Physically inactive ${ }^{c}$ & $40(16.6)$ & $9(4.0)$ & & \\
\hline Insufficiently active ${ }^{d}$ & $27(11.2)$ & $12(5.0)$ & & \\
\hline Active $^{\mathrm{e}}$ & $175(72.2)$ & $219(90.9)$ & & \\
\hline MPA $(n(\%))$ & & & 9.7 & $<0.001$ \\
\hline Physically inactive ${ }^{c}$ & $134(55.4)$ & $28(11,6)$ & & \\
\hline Insufficiently active ${ }^{d}$ & $34(14.0)$ & $44(18.2)$ & & \\
\hline Active $^{\mathrm{e}}$ & $74(30.6)$ & $170(70.2)$ & & \\
\hline \multicolumn{5}{|c|}{ Health-related quality of life $(0-100)$} \\
\hline General health & $47.3 \pm 15.9$ & $50.8 \pm 17.1$ & 3.1 & 0.002 \\
\hline Physical functioning & $74.0 \pm 21.3$ & $82.6 \pm 22.1$ & 6.7 & $<0.001$ \\
\hline Role limitations, physical & $73.0 \pm 24.9$ & $82.0 \pm 23.4$ & 5.1 & $<0.001$ \\
\hline Bodily pain & $68.1 \pm 27.3$ & $75.0 \pm 27.6$ & 3.6 & $<0.001$ \\
\hline Vitality & $71.7 \pm 23.5$ & $63.5 \pm 22.3$ & 4.5 & $<0.001$ \\
\hline Role limitations, emotional & $76.0 \pm 23.1$ & $83.2 \pm 21.7$ & 4.7 & $<0.001$ \\
\hline Mental health & $62.5 \pm 12.7$ & $76.6 \pm 19.2$ & 8.2 & $<0.001$ \\
\hline Social functioning & $80.6 \pm 24.0$ & $90.4 \pm 20.8$ & 5.9 & $<0.001$ \\
\hline Physical component & $68.7 \pm 18.1$ & $75.8 \pm 18.2$ & 6.6 & $<0.001$ \\
\hline Emotional component & $70.6 \pm 13.3$ & $80.3 \pm 16.4$ & 8.9 & $<0.001$ \\
\hline $\begin{array}{l}\text { ns: not significant. } \\
\text { a Data are presented as mean } \\
\text { b } p<0.05 . \\
\text { c Do not engage in PA. } \\
\text { d }<150 \mathrm{~min} / \text { week of PA. } \\
\text { e } \geq 150 \mathrm{~min} / \text { week of PA. }\end{array}$ & deviation or as $n$ & d percentages. & & \\
\hline
\end{tabular}

intervention. Despite all participants being offered access to the most appropriate PA sessions within the sport facility at the end of the intervention, most of them reported willing to continue exercising only with the same group and the same PA leader. It may suggest that a six-month PARS may be not be enough to maintain PA adherence at long-term if there is no continuity in the exercise groups but is effective in decreasing the number of inactive patients up to one year.

Behavioural programmes tailored to specific PA barriers and motivational factors together with receiving repeated PA prescription are warranted to maintain PA adherence after PA intervention. ${ }^{11}$. More randomised control trials are needed in assessing PA adherence at long-term after a PARS in sedentary patients with chronic conditions.

Aside from health benefits from increased physical activity, PARS provide positive effects on quality of life, similar to results of previous studies. ${ }^{24-26}$ Interestingly was the retention of the positive effects on perceived physical functioning, social functioning and on the emotional component up to one year. These improvements are especially significant among elderly people. Firstly, because an improved physical functioning allows independence and autonomy in the elderly avoiding the risk of falling, considered as one of the leading causes of hospitalization and responsible for high healthcare costs. ${ }^{27,28}$ Secondly, improvements in social functioning and in mental health may prevent elderly from the negative effects of increased risk of social exclusion and isolation. ${ }^{29}$ Taking into account that mental and social well-being is an integral and essential component of health ${ }^{30}$ PARS may have a greater impact in chronic ill patients.

Consistent with our findings, the last results from the overall implantation of the PAFES showed a decrease of sedentary behaviour in Catalan population from 2006 to 2013, especially in the target group of PARS, females (a decrease of 20\%) and adults aged 56-74 years old (a decrease of $34 \%){ }^{31}$ 
Table 2 Changes in physical activity level and health-related quality of life, pre- and post-intervention and at 12-month of follow-up assessment $(n=101)$.

\begin{tabular}{|c|c|c|c|c|c|}
\hline Variables $^{\mathrm{a}}$ & Pre & Post & 6-Months follow-up & Differences $x^{2}$ & $p^{\mathrm{b}}$ \\
\hline \multicolumn{6}{|l|}{ Physical activity (min/week) } \\
\hline Total PA & $473 \pm 493.6$ & $533.5 \pm 377.7$ & $387.9 \pm 345.5$ & 11.3 & 0.003 \\
\hline Vigorous PA & $54.8 \pm 201.3$ & $36.0 \pm 156$ & $19.6 \pm 113$ & 8.6 & 0.013 \\
\hline Moderate PA (MPA) & $170 \pm 294.3$ & $233.1 \pm 213$ & $146.7 \pm 203.3$ & 20.0 & $<0.001$ \\
\hline Walking & $247.8 \pm 235.3$ & $243.7 \pm 212.7$ & $217.5 \pm 200.2$ & ns & ns \\
\hline \multicolumn{6}{|l|}{ Physical activity (days/week) } \\
\hline MPA & $1.9 \pm 2.4$ & $3.2 \pm 2.0$ & $1.9 \pm 1.8$ & 23.2 & $<0.001$ \\
\hline Walking & $4.2 \pm 2.6$ & $4.7 \pm 2.5$ & $3.9 \pm 2.6$ & ns & ns \\
\hline MPA and walking $(n(\%))$ & & & & 28.7 & $<0.001$ \\
\hline Physically inactive & $14(14.0)$ & $4(4.3)$ & $12(11.7)$ & & \\
\hline Insufficiently active ${ }^{d}$ & $9(9.0)$ & $7(6.5)$ & $17(16.5)$ & & \\
\hline Active $^{\mathrm{e}}$ & $78(77.0)$ & $90(89.1)$ & $72(71.8)$ & & \\
\hline MPA $(n(\%))$ & & & & 30.3 & $<0.001$ \\
\hline Physically inactive & $51(50.0)$ & $19(18.5)$ & $35(34.3)$ & & \\
\hline Insufficiently active ${ }^{d}$ & $19(19.0)$ & $14(14.1)$ & $28(28.2)$ & & \\
\hline Active $^{\mathrm{e}}$ & $31(31.0)$ & $68(67.4)$ & $38(37.9)$ & & \\
\hline \multicolumn{6}{|c|}{ Health-related quality of life $(0-100)$} \\
\hline General health & $48.8 \pm 18.0$ & $48.6 \pm 15.7$ & $48.8 \pm 16.2$ & ns & ns \\
\hline Physical functioning & $73.0 \pm 20.8$ & $78.5 \pm 23.4$ & $82.8 \pm 21.0$ & 18.2 & $<0.001$ \\
\hline Role limitations, physical & $75.6 \pm 23.7$ & $76.6 \pm 24.8$ & $80.5 \pm 25.5$ & ns & ns \\
\hline Bodily pain & $67.0 \pm 27.4$ & $70.4 \pm 27.4$ & $70.4 \pm 29.3$ & ns & ns \\
\hline Vitality & $65.3 \pm 23.0$ & $67.6 \pm 23.1$ & $68.0 \pm 24.5$ & ns & ns \\
\hline Role limitations, emotional & $76.5 \pm 24.5$ & $80.0 \pm 22.2$ & $84.2 \pm 23.0$ & 7.5 & 0.024 \\
\hline Mental health & $69.3 \pm 22.2$ & $76.4 \pm 19.0$ & $74.0 \pm 21.0$ & 14.3 & $<0.001$ \\
\hline Social functioning & $80.6 \pm 24.0$ & $91.0 \pm 20.2$ & $90.4 \pm 20.0$ & 26.4 & $<0.001$ \\
\hline Physical component & $48.7 \pm 13.8$ & $50.1 \pm 14.3$ & $52.0 \pm 14.0$ & ns & ns \\
\hline Emotional component & $55.3 \pm 13.0$ & $60.0 \pm 12.0$ & $59.0 \pm 13.0$ & 18.3 & $<0.001$ \\
\hline
\end{tabular}

ns: not significant.

a Data are presented as mean \pm standard deviation or as numbers and percentages.

b $p<0.05$.

c Do not engage in PA.

d $<150 \mathrm{~min} /$ week of PA.

e $\geq 150 \mathrm{~min} /$ week of PA.

Primary care interventions based on PA are equally costeffective than drug interventions ${ }^{32}$ and in most of the cases, could yield to more profound and sustainable gains in health than drugs. ${ }^{33}$ In addition, existing randomised trial suggests that exercise and many drug interventions are often potentially similar in terms of their mortality benefits in the secondary prevention of cardiovascular diseases and prevention of diabetes. ${ }^{34}$

This research provides new information about PARS effectiveness in the Catalan primary care setting and it is important to consider that it was performed under real conditions with the consequent advantages and handicaps. The strengths of this study are based on the intervention itself, as it is part of a community programme lead by the Catalan Sports Council and the Department of Health of the Government of Catalonia. Furthermore, it is one of the first primary care-based PA programme in Catalonia extending the knowledge of PA benefits in general population with chronic conditions.

We have some limitations in the study. First, the use of subjective assessments may over/under-estimated results.
Secondly, the use of two types of questionnaires administered, by telephone interviews and self-administered may have influenced the validity of the response. The limited sample size and the sampling can introduce a number of biases and the results can only be extrapolated as normative to the population under study.

In conclusion, our results showed that PARS are effective and easily practicable method for increased PA and quality of life in routine primary care patients. In addition, PARS promote increased PA in a wide part of the population who otherwise are hard to reach or have a low motivation for lifestyle changes. This type of exercise intervention empowers the necessity to include supervised healthy PA programmes in sport facilities and healthy community opportunities to engage sedentary people to be more physically active.

Future research should investigate the impact of the PAFES programme on PA level from primary care providers and on patients' counselling and recruitment rates. 


\section{Funding}

The project was supported by a PhD fellowship by the Agency for Management of University and Research Grants (AGAUR).

\section{Conflict of interest}

Authors declare that they do not have any conflict of interests.

\section{Acknowledgments}

The authors would like to thank all patients, general practitioners, collaborating nurses and physical activity professionals for their support and implication in this project. We thank all the members of the PAFES group for being a part of this project: Lidia Ferrer, Albert Navarrete, Daniel Lara, Divina Farreny, Carles Ferré and Igor Labaien. We would like to acknowledge Dr. Mario LLoret for their help in the pilot project and their support in the present study. We thank the students who helped in data recollecting and processing: Ernest Cardona, Esther Guerrero and Alba Meda.

\section{References}

1. Lee IM, Shiroma EJ, Lobelo F, Puska P, Blair SN, Katzmarzyk PT. Effect of physical inactivity on major non-communicable diseases worldwide: an analysis of burden of disease and life expectancy. Lancet. 2012;380:219-29.

2. NICE. Four commonly used methods to increase physical activity: brief interventions in primary care, exercise referral schemes, pedometers and community-based exercise programmes for walking and cycling. National Institute for Clinical Excellence; 2006.

3. Orrow G, Kinmonth AL, Sanderson S, Sutton S. Effectiveness of physical activity promotion based in primary care: systematic review and meta-analysis of randomised controlled trials. BMJ. 2012;344:e1389.

4. Giné-Garriga M, Martin-Borràs C. Programa de Promoción de Actividad Física en los Centros de Atención Primaria (PPAF). Estudio piloto Atencion primaria/Sociedad Espanola de Medicina de Familia y Comunitaria. 2008;40:374-5.

5. Garcia-Ortiz L, Grandes G, Sanchez-Perez A, Montoya I, IglesiasValiente JA, Recio-Rodriguez JI, et al. Effect on cardiovascular risk of an intervention by family physicians to promote physical exercise among sedentary individuals. Rev Esp Cardiol. 2010;63:1244-52.

6. Enquesta de Salut de Catalunya (ESCA). Departament de Salut. Generalitat de Catalunya; 2011. Available from: www.gencat.cat/salut/esca

7. Lobelo F, Duperly J, Frank E. Physical activity habits of doctors and medical students influence their counselling practices. $\mathrm{Br} \mathrm{J}$ Sports Med. 2009;43:89-92.

8. Plan of physical activity and health (PAFES). Government of Catalonia; 2007.

9. WHO, Geneva Global Recommendations on Physical Activity for Health; 2010.

10. Harrison RA, Roberts C, Elton PJ. Does primary care referral to an exercise programme increase physical activity one year later? A randomized controlled trial. J Public Health (Oxf). 2005;27:25-32.
11. Grandes G, Sanchez A, Montoya I, Ortega Sanchez-Pinilla R, Torcal J. Two-year longitudinal analysis of a cluster randomized trial of physical activity promotion by general practitioners. PLoS ONE. 2011;6:e18363.

12. Prochaska JO, Velicer WF. The transtheoretical model of health behavior change. Am J Health Promotion. 1997;12: 38-48.

13. Guia de prescripció d'exercici físic per a la salut (PEFS). Generalitat de Catalunya; 2007.

14. Craig CL, Marshall AL, Sjostrom M, Bauman AE, Booth ML, Ainsworth BE, et al. International physical activity questionnaire: 12 -country reliability and validity. Med Sci Sports Exerc. 2003;35:1381-95.

15. Román Viñas B, Ribas Barba L, Ngo J, Serra Majem L. Validación en población catalana del cuestionario internacional de actividad física. Gac Sanit. 2013;27:254-7.

16. Alonso J, QualityMetric. Cuestionario de Salud SF-12. Ware JE Jr, Kosinski M, Keller SD. A 12-item short-form health survey: construction of scales and preliminary tests of reliability and validity. Med Care 1996; 34:220-33.

17. Pavey T, Taylor A, Hillsdon M, Fox K, Campbell J, Foster C, et al. Levels and predictors of exercise referral scheme uptake and adherence: a systematic review. J Epidemiol Community Health. 2012;66:737-44.

18. James DV, Johnston LH, Crone D, Sidford AH, Gidlow C, Morris C, et al. Factors associated with physical activity referral uptake and participation. J Sports Sci. 2008;26:217-24.

19. Dishman RK. In: Champaign H, editor. Exercise adherence; its impact on public health. Champaign, IL, England: Human Kinetics Publishers; 1994.

20. Pentecost C, Taket A. Understanding exercise uptake and adherence for people with chronic conditions: a new model demonstrating the importance of exercise identity, benefits of attending and support. Health Educ Res. 2011;26: 908-22.

21. Bennett JA, Winters-Stone K. Motivating older adults to exercise: what works? Age Ageing. 2011;40:148-9.

22. Hillsdon M, Foster C, Cavill N, Crombie H, Naidoo B. The effectiveness of public health interventions for increasing physical activity among adults: a review of reviews. London: Health Development Agency; 2005. p. 1-40.

23. Williams $\mathrm{NH}$, Hendry $\mathrm{M}$, France $\mathrm{B}$, Lewis R, Wilkinson C. Effectiveness of exercise-referral schemes to promote physical activity in adults: systematic review. $\mathrm{Br} \mathrm{J}$ Gen Pract. 2007; 57:979-86.

24. Acree LS, Longfors J, Fjeldstad AS, Fjeldstad C, Schank B, Nickel $\mathrm{KJ}$, et al. Physical activity is related to quality of life in older adults. Health Qual Life Outcomes. 2006;4:37.

25. Bize R, Johnson JA, Plotnikoff RC. Physical activity level and health-related quality of life in the general adult population: a systematic review. Prev Med. 2007;45:401-15.

26. Kallings LV, Leijon M, Hellenius ML, Stahle A. Physical activity on prescription in primary health care: a follow-up of physical activity level and quality of life. Scand J Med Sci Sports. 2008;18:154-61.

27. Fiatarone Singh MA. Exercise and aging. Clin Geriatr Med. 2004;20:201-21.

28. Gama da Silva ZA, Gómez Conesa A, Ferreira Sobral M. Epidemiology of falls in the elderly in Spain. A systematic review. Rev Esp Public Health. 2008;82:43-56.

29. Rimer J, Dwan K, Lawlor DA, Greig CA, McMurdo M, Morley W, et al. Exercise for depression. Cochrane Database Syst Rev. 2012;7:CD004366.

30. WHO. The Ottawa charter for health promotion; 1986.

31. Gonzalez A, Cabezas C, Violan M, Rubinat M, Casadesús F, Coll D, et al. El Plan de Actividad Física deporte y salud (PAFES): una oportunidad para el trabajo en red basándose en los activos para 
la promoción de la salud en Cataluña. Girona: Promoción de la Salud; 2013.

32. Garrett S, Elley CR, Rose SB, O'Dea D, Lawton BA, Dowell AC. Are physical activity interventions in primary care and the community cost-effective? A systematic review of the evidence. $\mathrm{Br}$ J Gen Pract. 2011;61:e125-33.
33. Fineberg HVA. Successful and sustainable health system how to get there from here. N Engl J Med. 2012;366:1020-7.

34. Naci H, PA loannidis J. Comparative effectiveness of exercise and drug interventions on mortality outcomes: metaepidemiological study. BMJ. 2013;347:f5577. 